\title{
Factors Affecting Chinese Students' Decision Making toward Thai Universities
}

\author{
Hongzhi Yin, Athapol Ruangkanjanases, and Chenin Chen
}

\begin{abstract}
Thailand has been becoming a more favorable destination for Chinese students to continue their further study. In year 2012, there were 9329 Chinese students enrolled in a Thai Higher Education Institution $\mathbf{4 6 . 4 \%}$ of total foreign student population). Knowing why they decided to come and what affected their decision making are crucial for institutions to recruit more Chinese students, as well as for related authorizations to brain gain for further development of the country. Therefore, there were three main objects of this study: 1) to summarize main information channels which Chinese students were seeking for overseas higher education institutions, 2) to analyze the main factors those have either positive or negative effects on Chinese students' decision making toward Thai universities, and 3) to provide recommendations for both Thai higher education institutions and related authorizations. This study is both qualitative and quantitative research. The findings indicate that all factors could predict $58.9 \%$ of variance in the correctness of a student's decision, and all those factors were positively related to students' decision making.
\end{abstract}

Index Terms-Factors, international, Chinese, students, decision making, Thai, universities, recruitment.

\section{INTRODUCTION}

With the largest population, and the booming up economy, People's Republic of China has been playing a more important role in this global village. The stereotypy of "Factory China" is becoming "Market China". Not only its GDP grows up, but more and more Chinese families are getting richer and parents concern much about their only child. Chinese market in which is not only requiring consuming products or luxuries, but also desperately in need of services.

Educational service could be the most important in all. Official statistical information from the Ministry of Education of People's Republic of China [1] indicates that; in year 2013, high school graduates of China have shot up to 9.12 million who are applying for the National Matriculation Examination (NME). At the meanwhile, the promotion rate (rate of acceptance by a Chinese Higher Education Institution) of senior second school graduates reached $87 \%$, Undergraduate's population of China in 2013 reached 6.99 million (MEC 2013).

The Kingdom of Thailand has always been a China's very friendly partner. Since Thailand is located in the center of Southeast Asia, it is geographically close to China. The

Manuscript received February 14, 2014; revised April 14, 2014.

Hongzhi Yin, Athapol Ruangkanjanases, and Chenin Chen are with the Chulalongkorn Business School, Chulalongkorn University, Thailand (e-mail: hongzhiyin@live.com, athapol@cbs.chula.ac.th, chenin.c@chula.ac.th). education costin Thailand is considered low for Chinese. With Thai Government's open policiesand the coming ASEAN Economic Community (AEC) in 2015 that brings more opportunities to this region, Thailand has advantages in offering business opportunity, including international educational business.

Chinese students have become the major source of foreign students in Thailand since year 2006. The Office of Higher Education Commission of Thailand [2] indicates that there were 9329 Chinese students enrolled in a Thai higher education institutes (HEI) in year 2010, which was $46.4 \%$ of the total foreign student population.

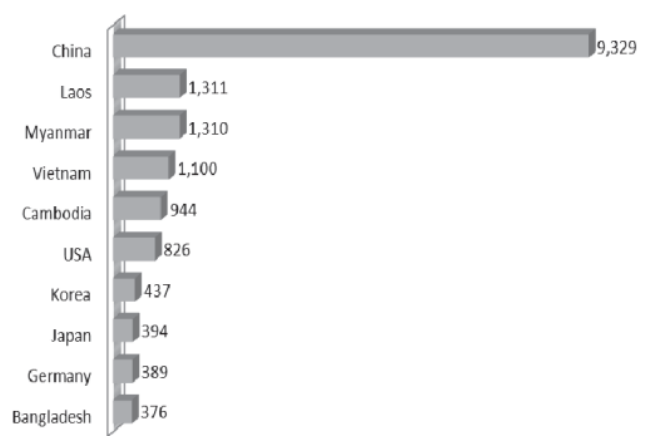

Fig. 1. Number of foreign students in Thailand (classified by country).

Suh Li Phang [3] mentioned that higher education (HE) has become an increasingly competitive sector. The number of countries that are actively involved in international student recruitment has grown considerably. Given the growing international competition between countries for international students, it has become increasingly important to gain a better understanding of the factors that influence international students' decision on study destination.

Therefore, in order to gain more Chinese students, realizing how students seek information of overseas higher education institutions and what influenced their final decisions to go on further study are crucial.

\section{LITERATURE REVIEW}

The blue book of Chinese students who graduated from Higher Education Institutions (HEIs) [4] indicated that "Undergraduates in 2013 who could get a job immediately after graduation was only $35 \%$ of the total population, lower than 2012 for $12 \%$.Master degree graduates in 2013 who were able to get a job immediately after graduation was only 26\% of the total population, lower than 2012 for 11\%".

\section{A. Decision-Making on Prioritization of Projects in Higher Education Institutions Using the Analytic Network Process Approach}

Nina Begi`cevi'c, Blaženka Divjak and Tihomir Hunjak [5] 
applied their research based on techniques used by Bouzaza, Arhaliass, Bouvier, and Alidi [6] to develop two scenarios to show how to include corporate strategy in the decision-making process and use the Analytic Network Process as a multiple criteria decision-making methodology which can be used in solving project selection problems.

The researchers developed their BCR (Benefit, Cost, Risk) model for a decision making process.

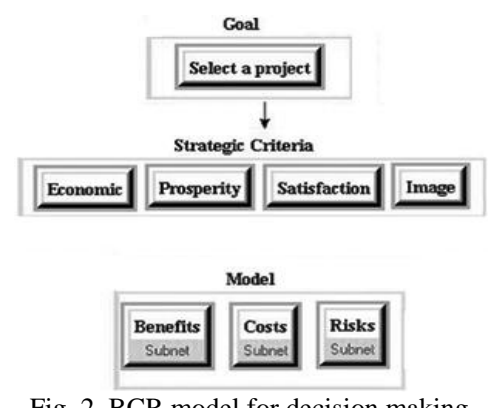

Fig. 2. BCR model for decision making.

There are goal, control criteria and sub-criteria in three control hierarchies, one each for the benefits, costs and risks of the decision and obtained their priorities from paired comparison matrices. Within the benefits, costs and risks (BCR) models, different clusters define interactions with respect to the control hierarchy. The benefits network indicates the alternatives that yield most benefits, whereas the costs and risks networks indicate the alternatives that are the most costly or pose the most risk on each alternative [7].

\section{B. The Evolution of Big Data and Learning Analytics in American Higher Education}

Based on the study of Anthony G. Picciano [8] from City University of New York, he developed a model to examine big data and analytics in American higher education. His tries to use information system to data mining useful information.

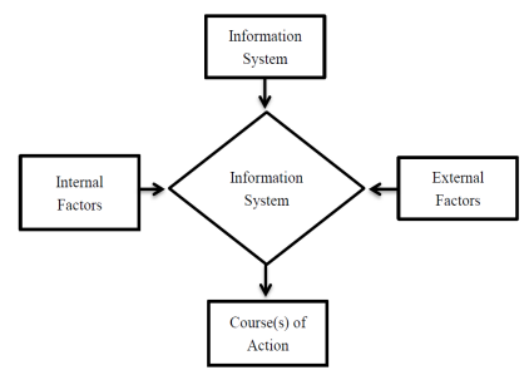

Fig. 3. Data-driven decision-making process.

The researcher found this model was very similar when students were making their decisions to screen out an overseas HEI. Therefore, in this study, the researcher decided to summarize student's information channels which students believed benefiting. External and internal influencing factors were included as sub-criteria to demonstrate how students' decisions were affected.

\section{RESEARCH Methodology}

\section{A. Conceptual Framework}

The conceptual framework of this study was comprised by three parts, Information Channel guides respondents to different sets of question according to their answers, common questions were followed including two External Factors and three Internal Factors as independent variables which were assumed to have either positive of negative effect on students' decision making. The correctness of a decision was taken as the only dependent variable (Fig. 4).

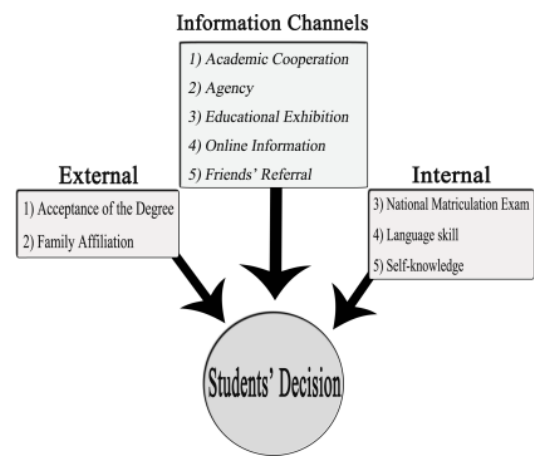

Fig. 4. Conceptual framework.

Based on the conceptual framework, hypotheses of this study were as follows:

H1: All of the following factors are significantly influential to Chinese students' decision making toward continuing their higher education in Thailand.

External factors:

1) Acceptance of the degree from Chinese Ministry of Education

2) Family affiliation

Internal factors:

1) National Matriculation Exam

2) Language skill

3) Self-knowledge of the destination country

\section{B. Data Collection}

The researcher interviewed 20 Chinese students by both face-to-face and phone interview. Both online questionnaire and paper-printed questionnaire were distributed in order to cover students all over Thailand.

Using 95 percent confidence level with sampling error of 5 percent based on Yamane [9], sample size of Chinese students was 385.The researchers used the convenient sampling technique for data collection. Questionnaires were distributed to both public and private universities located in Thailand. The survey was conducted between September and November 2013. Total of 202 completed questionnaires were returned. Therefore the sampling error of 7 percent was applied instead of 5 percent as originally planned.

\section{Measurement}

The questionnaire was consists of four parts including: $P A R T$ 1) Demographic information of a respondents; PART 2) Information channels; PART 3) Influencing factors, and PART 4) Students' satisfaction of their own decision.

The researchers used a five-point-Likert scale, ranging from 1 to 5 as follows; 1) Strongly Disagree, 2) Disagree, 3) Uncertain, 4) Agree, and 5) Strongly Agree.

Respondents would be guided to different sets of question according to their information channels. Influencing factor questions were followed as must-answer questions, at the end, students were asked how they felt about the correctness of their decision of studying in Thailand. PART 3 and 4 was 
analyzed by inferential statistics, while PART 2) Information channels as the origin of students' decisions were taken as external influencing factors and result of analysis was demonstrated descriptively.

\section{External Factors (Independent Variables)}

The external independent variables including: Academic cooperation; Agency; Educational exhibition; Online information; Friends' referral; Acceptance of the degree from Chinese Ministry of Education; Family affiliation

1) Academic cooperation questions were asking how well their previous school assisted them to go on their further study abroad.

2) Agency questions were about their agencies responsiveness, information given was accurate, and fee charged was fair.

3) Education exhibition questions were measuring how students perceive overseas HEI during the exhibition and its serviceability.

4) Online information questions were about the ease of students to apply a overseas HEI online, the design of their websites and its creditability.

5) Friends' referral questions were measuring their friends' influences toward their final decisions.

6) Acceptance of the degree from Chinese Ministry of Education questions were asking students how much they care about their future degree's availability.

7) Family affiliation questions were measuring how much students' families were supporting them both financially and psychologically.

\section{E. Internal Factors (Independent Variables)}

The external independent variables including: National Matriculation Exam; Language skill; Self-knowledge of the destination country

1) National Matriculation Exam as the most important exam for students to gain permission of entering a Chinese HEI. Questions were asked about their exam performance and its effects.

2) Language skill questions were measuring students' language skills before they start their overseas study.

3) Self-knowledge of the destination country questions were asking how much students were prepared and aware of their future life and study environment.

\section{F. Dependent Variable}

The only dependent variable in this study was to measure how much students were satisfied with their own decision of continuing their further study in a Thai HEI.

\section{DATA ANALYSIS}

TABLE I: NuMBERS AND PERCENTAGES OF THE RESPONDENTS ClASSIFIED BY PERSONAL DEMOGRAPHY $(N=202)$

\begin{tabular}{lcc}
\hline Personal Factor & Number & Percentage \% \\
\hline Gender & & \\
Female & 110 & 54.5 \\
Male & 92 & 45.5 \\
\hline Age & & \\
$19-22$ & 102 & 50.5 \\
$23-26$ & 55 & 27.2
\end{tabular}

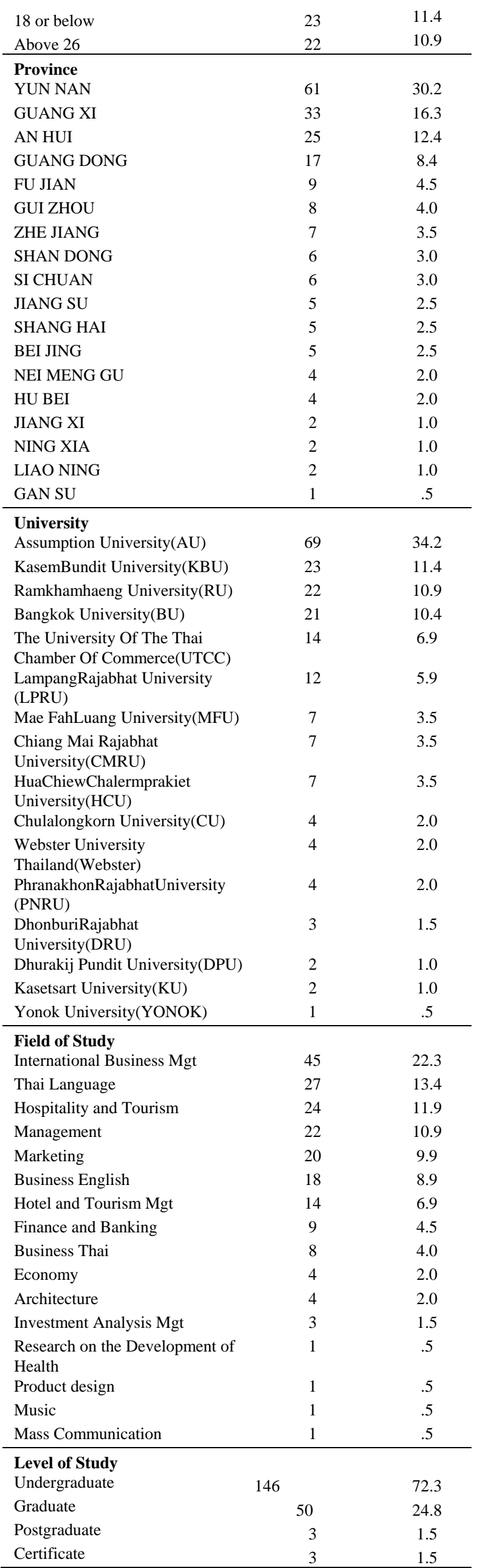


By using all 202 statistically valid questionnaires, the researcher used SPSS Version 19 to analyze the variables. Descriptive statistics including frequency, percentage, mean, and standard deviation were used to list the demographic information of respondents (referring Part 1 \& Part 2). Inferential statistics was used to test the hypothesis including: multiple regression and correlation analysis, in the purpose of finding its significance. (Referring Part 3).

From all 202 valid feedbacks, the researchers summarized the findings into three main parts as follows:

\section{Part 1: Demographic Data of Respondents}

Table I showed that female students $(54.5 \%)$ were slightly more than male students, respondents age between $19-22$ were the majority $(50.5 \%)$, and most of the students came from YUNNAN (30.2\%), GUANGXI (16.3\%), and ANHUI (12.4\%). Universities with the most Chinese students' population were Assumption University (34.2\%). Most students were studying their bachelor degree in Thailand $(72.3 \%)$, and the favorable fields of study were: International Business Management (22.3\%), Thai Language (13.4\%), Hospitality and Tourism Management (11.9\%).

Fig. 5 indicated that Educational agency ranks the first, which 86 students $(42.6 \%)$ made their final decisions through an agency. Friend referral ranks second with 45 students. (22.3\%) Joint program or academic cooperation ranks third with 41 students. (20.3\%), follows 17 students from Online information (8.4\%) and 13 students from Educational exhibitions $(6.4 \%)$.

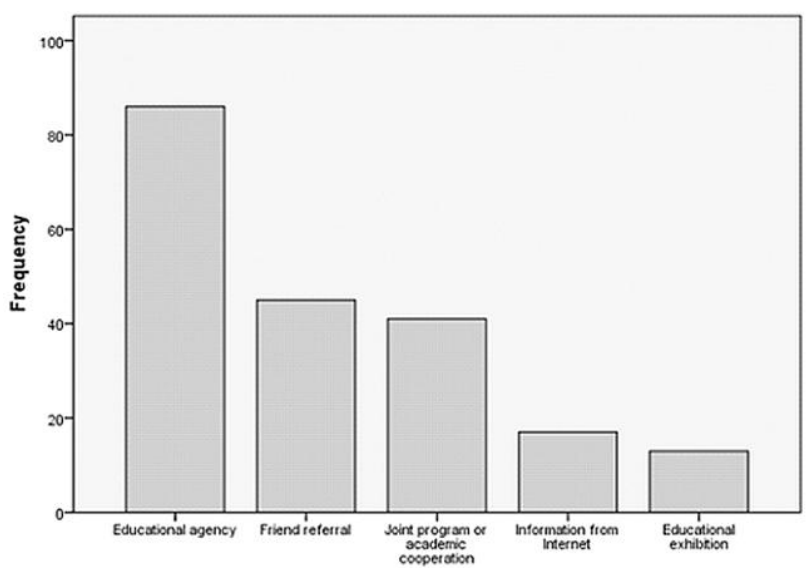

Fig. 5. Information channels.

\section{Part 2: Internal and External Influencing Factors}

In accordance to the feedbacks about all ten influencing factors indicated in Table II, students were uncertain about their satisfaction toward information from Joint programs (Mean=3.17, $S D=0.934$ ) and Agencies (Mean=3.1, $S D=0.984)$, students agree that they are satisfied with Educational exhibition (Mean=3.64, $S D=1.077$ ), Online Information (Mean=3.56, $S D=0.893)$, and Friends' referral (Mean=3.49, $S D=0.796)$.

Students agree that future Acceptance of the degree from Chinese Ministry of Education (Mean=3.73, $S D=1.063)$ and Family reasons $(M e a n=3.81, S D=0.952)$ affected their final decision making.

Regarding to students themselves, they were not sure whether the NME score (Mean=3.24, $S D=1.171)$ and their Self-knowledge of the destination country (Mean=3.2.79, $S D=1.122)$ were influential to their decisions. However, students believed that Skill language (Mean=3.5, $S D=1.032)$ was affecting their final decision making.

TABLE II: SUMMARIZATION OF INFLUENCING FACTORS

\begin{tabular}{|c|c|c|c|}
\hline \multicolumn{4}{|c|}{ Decision making factors $(n=202)$} \\
\hline External & Mean & Std.deviation & Definition \\
\hline $\begin{array}{l}\text { 1) Joint program or } \\
\text { academic cooperation }\end{array}$ & 3.17 & 0.934 & Uncertain \\
\hline 2) Educational agency & 3.1 & 0.984 & Uncertain \\
\hline 3) Educational exhibition & 3.64 & 1.077 & Agree \\
\hline $\begin{array}{l}\text { 4) Information from } \\
\text { Internet }\end{array}$ & 3.56 & 0.893 & Agree \\
\hline 5) Friend referral & 3.49 & 0.796 & Agree \\
\hline $\begin{array}{l}\text { 6) Acceptance of the } \\
\text { degree from Chinese } \\
\text { Ministry of Education }\end{array}$ & 3.73 & 1.063 & Agree \\
\hline 7) Family affiliation & 3.81 & 0.952 & Agree \\
\hline \multicolumn{4}{|l|}{ Internal } \\
\hline $\begin{array}{l}\text { 8) National Matriculation } \\
\text { Exam (NME) }\end{array}$ & 3.24 & 1.171 & Uncertain \\
\hline 9) Language skill & 3.5 & 1.032 & Agree \\
\hline $\begin{array}{l}\text { 10) Self-knowledge of } \\
\text { the destination country }\end{array}$ & 2.79 & 1.122 & Uncertain \\
\hline $\begin{array}{l}\text { 11) Overall Correctness } \\
\text { of a Decision }\end{array}$ & 3.54 & 0.44 & AGREE \\
\hline
\end{tabular}

TABLE III: CORRELATIONS BETWEEN VARIABLES $(N=202), P<.001$

\begin{tabular}{|l|r|r|r|r|r|}
\hline & Family Affiliation. & NME & Language Skill & Self-Knowledge & Overall Decision. \\
\hline Degree Acceptance & .066 & .134 & .152 & .046 & .589 \\
\hline Family Affiliation & 1 & .183 & -.108 & -.208 & .182 \\
\hline NME & & 1 & -.107 & .125 & .486 \\
\hline Language Skill & & & 1 & .316 & .411 \\
\hline Self-Knowledge & & & & 1 & .339 \\
\hline Overall Decision & & & & & 1 \\
\hline
\end{tabular}

Pearson's product-moment correlation was conducted and the result showed that all factors were positively related to the dependent variable: Correctness of a decision, in which Degree acceptance (.589) ranks first, second was the NME score (.486), third students' language skill (.411), follows students' self-knowledge (.339) and Family affiliation (.182).
Part 3: Hypothesis testing of Factors Affecting Chinese Students' Decision Making toward Thai Universities

Multiple regressions were conducted to test whether all five factors were significant to influence student's decision making. 
H1: All factors:1) Acceptance of the degree from Chinese Ministry of Education 2) Family affiliation 3) National Matriculation Exam 4) Language skill 5) Self-knowledge of the destination country are significantly influential to Chinese students' decision making toward continuing their higher education in Thailand.

When using multiple regression, the adjusted $\mathrm{R}^{2}$ was 0.696 . Fig. 6 indicated the result of the analysis.

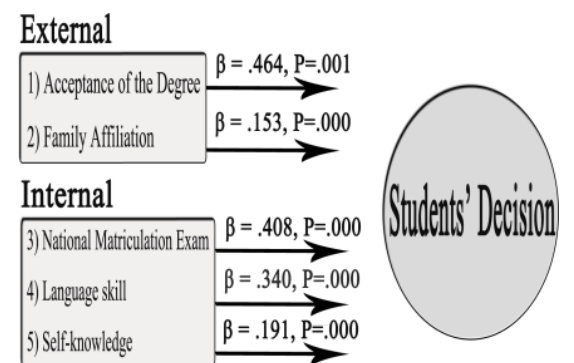

Fig. 6. Correlations between variables $(n=202), p<.001$.

Based on the result, all five factors were significantly valid. ( $P$-values were less than .05). All dependent variables (Both external and internal factors) were positively related to dependent variable, $\mathrm{H}_{1}$ was accepted.

Therefore, all factors are significantly influential to Chinese students' decision making toward continuing their higher education in Thailand.

To conclude the findings, five factors are able to predict $69.6 \%$ of the variance of this model (Adj. $R^{2}=.696$ ). Acceptance of the future degree ranks first that would affect students' decision making. $(\beta=.464, P=.001)$, National Matriculation Exam score ranks second influential. $(\beta=.408$, $P=.000)$, follows by Language skill $(\beta=.340, P=.000)$; Self-Knowledge $(\beta=.191, P=.000)$ and Family Affiliation $(\beta$ $=.153, P=.000)$.

\section{DISCUSSION AND RECOMMENDATION}

\section{A. About Information Channels and Recruitment}

Recommendations were given according to the rank of each factor.

1) Agency: Any Thai HEI plans to recruit Chinese students through an agency shall first consider the qualification of the agency by checking the list of qualified agencies on the website of Ministry of Education, PRC; the list is available and categorized by provinces on the webpage of the Chinese Overseas Students Monitoring system affiliated to the Ministry of Education, China (JSJ) [10]. Thai HEIs should consider the cost of outsourcing the recruitment to an agency. Also, the way of the agency recruits should be closely monitored by the institution in case of ruining the image. From the statistic result, the researcher suggests that agencies should not be allowed to charge students heavily. Over-charged fee brought up students' expectation to a Thai HEI; hence, a bigger gap between expectation and perception brings more possibilities of dissatisfaction.

2) Friends' referral: Asmuss and Svennevig [11] mentioned in their study that "Social systems theory observes that decision making as communication that opens future alternatives of action."They believe that decision making is achieved in organized sequences of talk-in-interaction based on the turn-taking mechanism.

The research findings indicated that the reputation of an institution and positive word of mouth could bring it more and more students. Chinese students prefer to believe in information from their friends, and their resistance toward marketing activities would be reduced, and tend to be self-motivated in the purpose of being with their friends. The researchers suggest Thai HEIs maintain the satisfaction level of current Chinese students, as well as getting feedbacks from them frequently. If an institution has not gotten any Chinese students, all five information channels mentioned could be considered as touch points with the potential candidates according to the institution's qualification and budget.

3) Joint programs and academic cooperation: More and more Thai HEIs have developed relationships with Chinese HEIs; $20.3 \%$ of students came from joint programs and academic cooperation. A Thai HEI could screen relatively equivalent Chinese HEI as a partner to develop majors that Chinese students were more interested in, Such as business administration, Thai language, hotel and tourism management.

Before-departure orientations should be given before students join the program to help Chinese students gain ideas about Thailand and the Thai HEI. If budget allows, the management of the Chinese HEI could be invited for a campus tour to Thailand. The tour should also include potential students as well as their parents.

The researchers strongly recommend that Thai HEIs to establish partnerships not only with Chinese HEIs but also well-developed Chinese high schools. Thai HEIs could start with exchange visitors between both Thai students and Chinese students; language exchange courses or culture experience courses are both popular. Or, Thai HEIs could simply recruit for a summer camp for Chinese students to come to Thailand. Students in their first or second year of study were recommended as candidates. Time of period should be in the range of one to three weeks. Thai HEIs should pay special attentions on providing proper and safe accommodation; summer camp activities should be led by HEI staff instead of $100 \%$ outsourced to a tour agency. One of the most concerns of the Chinese parents was the safety of their only child.

Cooperating with high schools was one of the fastest ways of gaining awareness and word of mouth; well-planned partnership and operations would turn those into ever-ending students' resources with a relatively lower marketing activity cost.

1) Online information: Online information is still playing an important role in the recruitment process. Even though, Students expressed their dissatisfaction toward the late or non-reply of the on-line registration system. Poor design of the website could also be another reason for students to leave the HEI's official website fast and seek for information from other sources. Thai HEI should consider search engine marketing, but most importantly, instead of using Google, BAIDU is recommended since Google withdraws its service from mainland China and more than $80 \%$ of Chinese is using 
BAIDU as their default search engine.

A Thai HEI should consider improving its website content with more pictures, or any kind of visual aids, increase the ease of online enrollment and registration process; Chinese language interface shall be developed, not only for students, but also their parents.

2) Educational exhibitions: Thai HEIs' educational exhibitions were held in several provinces in mainland China annually, mostly held by a local ministry of education. Surprisingly, only $6.4 \%$ of students came due to an educational exhibition. Main problems were: Disconnection with Thai HEI, Lack of follow-up, Language barrier, and Incapable staff at the exhibition.

Disconnection: Students might get very attracted by a Thai HEI, but not able to reach the Thai HEI after the exhibition ends. International phone calls are over controlled by the government which requires a certain amount of money deposit, as well as a registration of personal identification card. The whole process could take weeks before a Chinese student to make a phone call to Thailand.

Lack of follow-up: as mentioned above, it is not easy for Chinese students to directly call to Thailand, Thai HEIs should consider developing or outsourcing their recruitment to a local office, to record students' information and follow up after the exhibition ends. If the exhibition was not held during summer break (June - September), the researcher strongly recommends local recruiting office of the Thai HEI to make frequent contacts with students.

Language barrier: students graduated from high school were not capable to explore various kinds of information of the Thai HEIs, they were not familiar with the foreign curriculum as well, and confusion forced them to go to other channels.

Incapable staff at the exhibition: staff at the exhibition was either local Chinese people or Thai staff from a Thai HEI. Local Chinese staff might not be familiar with Thai policies, application procedure, and the Thai HEIs' staff might not be familiar with Chinese laws and policies, language, and concerns of Chinese students and parents. Current enrolled Chinese student is a good choice for assistance at the exhibition.

Even though education exhibition was one of the most creditable information sources in Chinese students' mind, it has not been well-developed and adapted.

\section{B. About Influencing Factors}

From the result of the statistical analysis, the key factor of all is: the approval and acceptance from Ministry of Education of China. Most students returned China after their overseas study, and the degree they gained would not be all valid back in mainland China. Students graduated from a disqualified university, or universities that were not on the list of the Ministry of Education will not be granted an equivalent degree. Both governmental section and private enterprises are paying attention to students' qualification; level of study was one of the most important criteria. The researchers suggest Thai HEIs start approaching the Ministry of Education of China as early as the institutions are ready to start their international programs. The approval procedure could be complex and time consuming. But, getting the approval is the most important ticket for start recruiting Chinese students. Otherwise, students would not waste their time and money getting a degree that is not valid back in their home country.

Thai HEIs could also start to accept the Chinese National Matriculation Examination (NME) score as one of the criteria when recruit. The NME is one of the most authoritative tests in mainland China. By looking at students' NME score could help HEIs to effectively screen out the most capable candidates. Better students' quality increases further education performances. Furthermore, increase or enhance Thai HEIs' image and reputation.

Accepting Chinese NME score would also increase students' convenience of application as well as shorten and simplify the application procedure.

\section{LIMITATION OF THE STUDY}

Since the interviews and questionnaires were given during the end of year 2013, which was also the end of the semester in Thailand. Many Chinese students went home after their final examinations; there were only 202 valid questionnaire respondents in this study. Consequently, because of time constraint, the researchers had to apply 7\% instead of 5\% sampling error as originally planned. Start distributing the questionnaires in different time periods and from different channels would be recommended.

\section{FUtURE RESEARCH}

The researchers only interviewed or distributed questionnaires to students who experienced Thai Higher Education service. However, in order to find out more accurate index and factors toward students' decision making, Chinese parents or High School graduates in China shall be included in the sample. Going to China around the middle of June is recommended, since all students finished their NMEs and are looking for a higher education institution.

\section{REFERENCES}

[1] Ministry of Education of People's Republic of China. (MEC). [Online]. Available:

http://www.moe.gov.cn/publicfiles/business/htmlfiles/moe/moe_2792

[2] Office of Higher Education Commission, Thailand (OHEC). [Online] Available: http://www.inter.mua.go.th/main2/index.php

[3] S. L. Phang, "Factors influencing international students' study destination decision abroad," Master in Communication Thesis, University of Gothenburg, Department of Applied Information Technology, Gothenburg, Sweden, January 2013.

[4] Mycos, "The blue book of Chinese students who graduated from higher education institutions," 2013 Chinese university students' employment report inMax institute, 2013.

[5] N. Begi'cevi'c, B. Divjak, and T. Hunjak, Decision-making on prioritization of projects in higher education institutions using the analytic network process approach, Springer-Verlag, pp. 353-355,2009

[6] D. Bouzaza, A. Arhaliass, J. M. Bouvier, and A. S. Alidi, "Use of the analytic hierarchy process to measure the initial viability of industrial projects," International Journal of Project Management, vol.14, no.4, pp.205-208, 1996.

[7] T. L. Saaty and Ozdemir, The Encyclicon: A dictionary of decisions with dependence and feedback based on the analytic network process, Pittsburgh: RWS Publications, 2005

[8] A. G. Picciano, "The evalution of big data and learning analytics in American higher education," Journal of Asynchronous Learning Networks, vol. 16, no. 3, pp. 9-20, 2012 
[9] T. Yamane, "Statistics, an introductory analysis," $2^{\text {nd }}$ Ed., New York: Harper and Row, 1967.

[10] Chinese Overseas Students Monitoring system affiliated to the Ministry of Education, China (JSJ). (2013). [Online]. Available: http://www.jsj.edu.cn/index.php/default/index/sort/12048

[11] B. Asmuss and J. Svennevig, "Meeting talk. An introduction," Journal of Business Communication, vol. 46, no. 1, pp. 3-22, 2009.

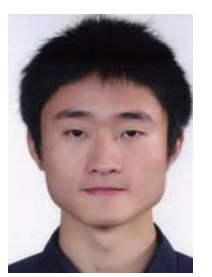

Hongzhi Yin is a student of master of management program in International Business, Chulalaongkorn Business School, Chulalongkorn University. He received his bachelor degree from Assumption University of Thailand, majoring in marketing. He taught at Kasem Bundit University and has been working for education service providers since year 2007.
Athapol Ruangkanjanases is a faculty member at Department of Commerce, Chulalongkorn Business School, Chulalonglorn University. He received his Ph.D. from Illinois Institute of Technology, USA. Before joining Chulalongkorn University, he was a full-time faculty member at the School of Management, Marist College, New York, USA.

Chenin Chen is an adjunct associate professor at Chulalongkorn Business School, Chulalonglorn University. He received his D.B.A. from United States International University, California, USA. He is the managing director of Rayong Wire Industries Public Company Limited and board director of Capital Engineering Network Public Company Limited and UaWithya Public Company Limited; all are listed companies in Stock Exchange Market of Thailand. 